\title{
Complications of Acute and Chronic Otitis Media in a Tertiary Referral Center in Nepal
}

\author{
Original Investigation $>\begin{aligned} & \text { Kripa Dongol (D), Pabina Rayamajhi } \mathbb{D} \text {, Urmila Gurung (D) } \\ & \text { Department of ENT-HNS, Tribhuvan University Teaching Hospital, Institute of Medicine, Maharajgunj, Kathmandu, Nepal }\end{aligned}$
}

\begin{abstract}
Objective: The aim of this study was to report the incidence of complications in otitis media and to determine the frequencies of various extracranial and intracranial complications at a tertiary care hospital.

Methods: We retrospectively reviewed the clinical records of patients of all ages and genders who were treated in a tertiary care hospital in Nepal from May 2015 to May 2020 for complications of acute and chronic otitis media. The complications were broadly classified as extracranial and intracranial. The details of patient profiles, histories, examination findings, investigations and treatments were reviewed from the charts.

Results: The mean age of 164 patients with complications of otitis media was $47.44 \pm 18.58$ years. There were $79(48.2 \%)$ male and 85 (51.8\%) female patients. The overall incidence of otitis media complications was $0.78 \%$. The incidences of the complications from
\end{abstract}

ORCID iDs of the authors: K.D. 0000-0001-5108-6770; P.R. 0000-0002-3763-0079; U.G. 0000-0001-7640-0199.

Cite this article as: Dongol K, Rayamajhi P, Gurung U. Complications of Acute and Chronic Otitis Media in a Tertiary Referral Center in Nepal. Turk Arch Otorhinolaryngol 2020; 58(4):234-40.

\section{Corresponding Author:}

Kripa Dongol; kripadongol@yahoo.com

Received Date: 10.07 .2020 Accepted Date: 29.09 .2020

Content of this journal is licensed under a Creative Commons Attribution 4.0 International License. Available online at www.turkarchotolaryngol.net

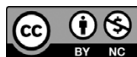

DOI: $10.5152 /$ tao.2020.5761

\section{Introduction}

Otitis media is the inflammation of the mucoperiosteal lining of the tympanomastoid compartment. The term complication denotes the spread of the infection beyond the mucosal lining of the middle ear cleft (1). Complications of otitis media could be life-threatening, with significant morbidity and mortality.

The complications of otitis media have been classified as intracranial and extracranial (2). They can occur secondary to acute or chronic otitis media rates of extracranial and intracranial complications are reported to range from $0.69 \%$ to $5 \%$, and the rate of mortality from intracranial complications as $8 \%(2)$.

Complications of otitis media are a common problem in developing countries (3). The factors responsible for such complications in developing countries could be poverty, lack of education, unavailability of healthcare facilities and ignorance about aural symptoms. In developed countries, however, complications can be caused by antibiotic resistance, with or without cholesteatoma. The prevalence acute otitis media, chronic otitis media without cholesteatoma, and chronic otitis media with cholesteatoma were $0.5 \%, 0.06 \%$ and 5.6\%, respectively. Extracranial complications, intracranial complications and combined extracranial and intracranial complications were seen in $80 \%, 11 \%$ and $9 \%$ of the patients, respectively. The most common extracranial and intracranial complications were subperiosteal abscesses and brain abscesses, respectively. There was one mortality due to complication.

Conclusion: The incidences of complications and mortality from otitis media have declined with the availability of suitable antibiotics, improved imaging, and multidisciplinary management. Antibiotic resistance and masking of signs and symptoms, however, could pose challenges in the future.

Keywords: Otitis media, middle ear, infection, cholesteatoma, complications masking of symptoms by antibiotics and change in the virulence of causative organisms (4).

The purpose of this study was to report the incidence of complications of otitis media and to determine the frequencies of various extracranial and intracranial complications at a tertiary care hospital.

\section{Methods}

A retrospective study was conducted in the department of Otorhinolaryngology of Tribhuvan University Teaching Hospital, Nepal from May 2015 to May 2020. During this study period, 20,797 patients were diagnosed with acute and chronic otitis media. Out of the 20,797 patients, 164 were diagnosed with a complication and their charts were retrospectively reviewed. Ethical approval was obtained on $7^{\text {th }}$ January 2020 from the Institutional Review Committee of Institute of Medicine, Tribhuvan University with protocol number of 278(6-11)E2 076/077. The study was conducted as per the ethical principles described by the Declaration of Helsinki. Informed consent was obtained from all patients. 
Patients of all age groups and genders with a complication of otitis media were included in the study. Complications from acute otitis media were identified in 34 patients, complications from chronic otitis media with cholesteatoma were identified in 123 patients, and complications from chronic otitis media without cholesteatoma were observed in seven patients. The details of patient profiles, histories, examination findings, investigations and treatments were reviewed from the charts. We used Microsoft Office Excel (Microsoft Corp.; Redmond, WA, USA) for data recording and analysis.

The complications of otitis media were classified as extracranial and intracranial. Extracranial complications were mastoiditis, mastoid abscess, mastoid fistula, Bezold's abscess, Luc's abscess, zygomatic abscess, facial nerve paralysis, labyrinthitis and labyrinthine fistula. Intracranial complications were meningitis, brain abscess, extradural abscess, subdural abscess, lateral sinus thrombophlebitis and otitic hydrocephalus.

\section{Results}

During the five-year study period, 164 patients were diagnosed with complications of otitis media, of whom 79 (48.2\%) were male and 85 (51.8\%) were female. The incidence of complications from otitis media was $0.78 \%$. The incidences of complications from different types of otitis media are shown in Table 1.

The age of the patients with complications ranged from seven months to 89 years, with a mean age of $47.44 \pm 18.58$ years. The mean age of patients with complications from acute otitis media was $23.76 \pm 19.68$ years. Complications of otitis media were more common in young patients (0 to 20 years) as shown in Figure 1. Similarly, acute otitis media complications were more common in the younger age group ( 0 to 10 years) as shown in Figure 2. The distribution of extracranial and intracranial complications according to age groups are shown in Tables 2 and 3, respectively.

Among the 164 patients, 155 extracranial complications and 27 intracranial complications were identified. Fifteen out of 164 patients (9\%) had more than two complications. The most common co-existing complications were facial palsy and acute

\section{Main Points}

- The incidence of complications of acute and chronic otitis media was found to be $0.78 \%$.

- The incidence of complications from acute otitis media has declined with antibiotic use in comparison to the incidence of complications from chronic otitis media.

- The highest incidence of complications was seen in patients aged younger than 20 years.

- The incidence of intracranial complications has declined in comparison to that of extracranial complications.

- Clinicians should be vigilant about the possibility of multiple complications in a single patient.
Table 1. Incidences of complications in different types of otitis media

\begin{tabular}{l|c|c|c}
\hline Type of otitis media & $\begin{array}{c}\text { Number of } \\
\text { patients with } \\
\text { otitis media }\end{array}$ & $\begin{array}{c}\text { Number of } \\
\text { patients with } \\
\text { complication }\end{array}$ & $\begin{array}{c}\text { Incidence of } \\
\text { complication } \\
(\%)\end{array}$ \\
\hline AOM & 6,749 & 34 & 0.5 \\
\hline COM with cholesteatoma & 2,189 & 123 & 5.6 \\
\hline COM without cholesteatoma & 11,859 & 7 & 0.06 \\
\hline
\end{tabular}

AOM: Acute otitis media; COM: Chronic otitis media

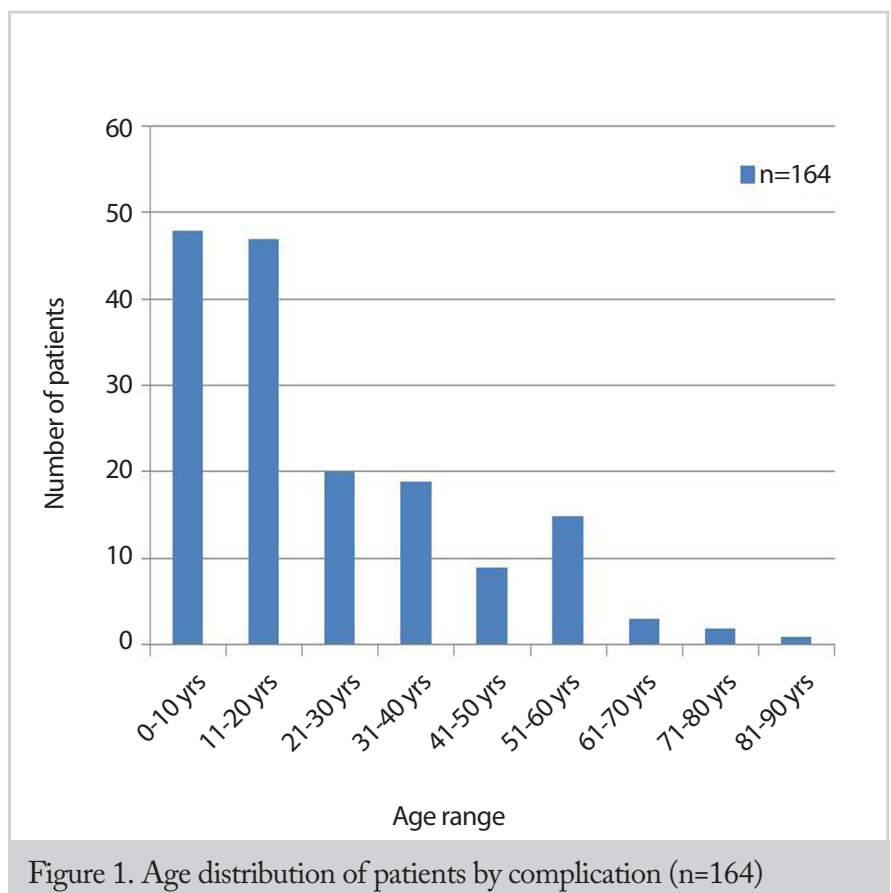

Figure 1. Age distribution of patients by complication $(n=164)$

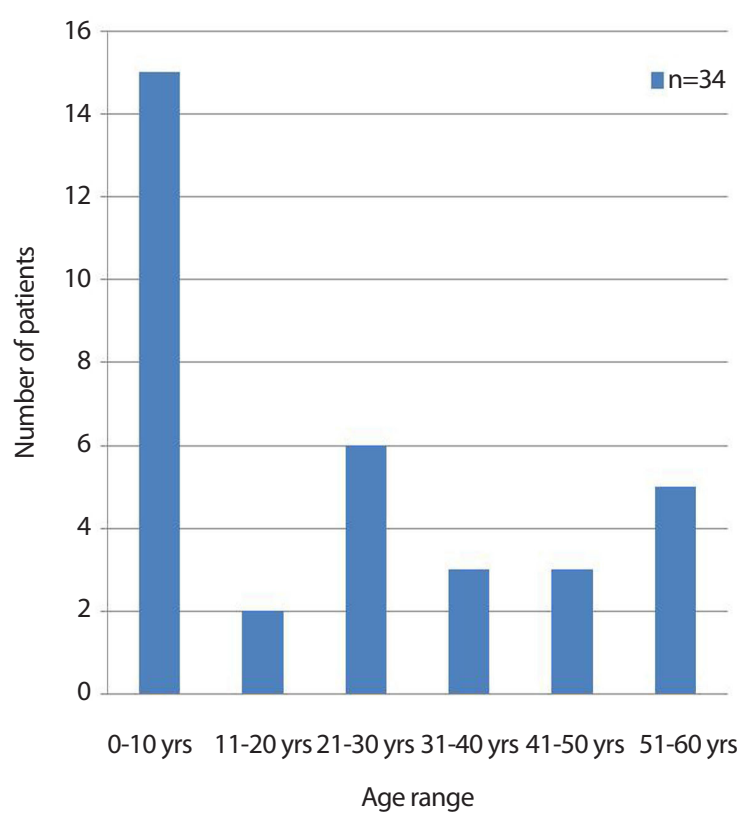

Figure 2. Age distribution of patients by complications from acute otitis media $(n=34)$ 
Dongol et al.

236 Complications of Otitis Media

Turk Arch Otorhinolaryngol 2020; 58(4): 234-40

Table 2. Distribution of extracranial complications according to age groups ( $\mathrm{n}=155)$

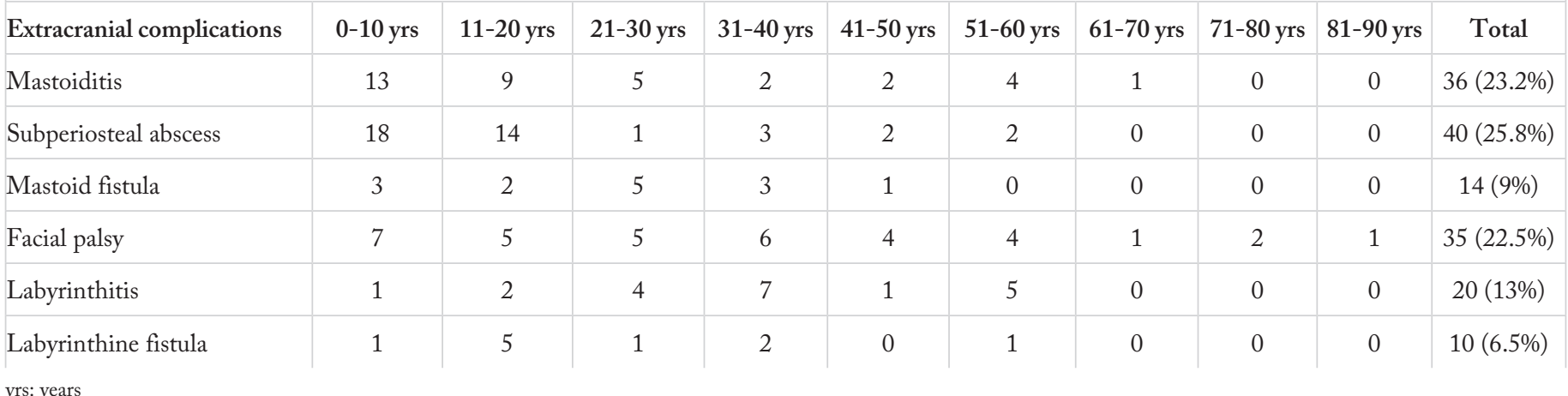

yrs: years

Table 3. Distribution of intracranial complications according to age groups $(n=27)$

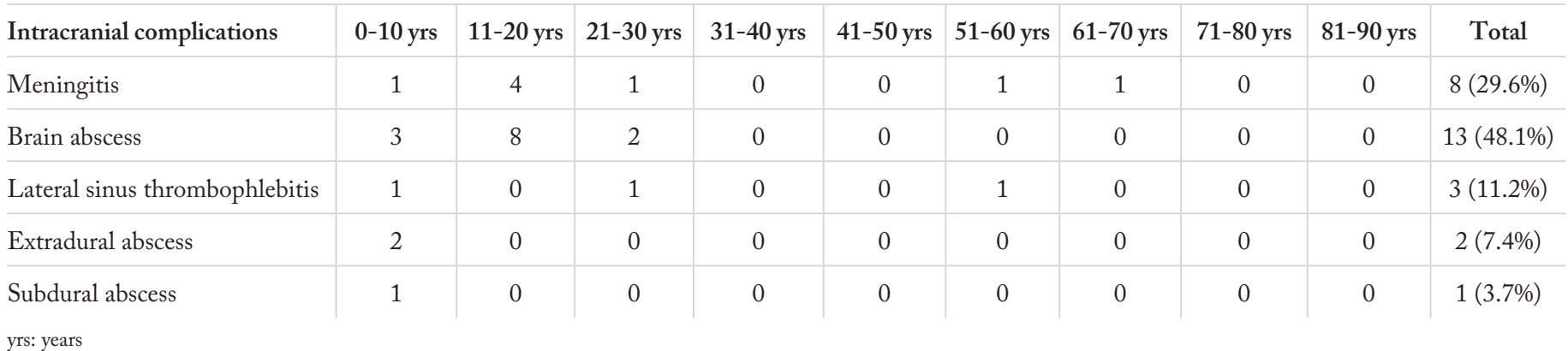

yrs: years

Table 4. Distribution of extracranial complications by types of otitis media $(n=155)$

\begin{tabular}{l|c|c|c|c|}
\hline Extracranial complication & Acute otitis media & $\begin{array}{c}\text { Chronic otitis media (without } \\
\text { cholesteatoma) }\end{array}$ & $\begin{array}{c}\text { Chronic otitis media } \\
\text { (with cholesteatoma) }\end{array}$ \\
\hline Mastoiditis & 18 & 3 & 15 & $36(23.2 \%)$ \\
\hline Mastoid abscess & 2 & 0 & 34 & $2(1.3 \%)$ \\
\hline Bezold's abscess & 0 & 0 & 0 & $1(0.6 \%)$ \\
\hline Luc's abscess & 1 & 0 & 1 & $1(0.6 \%)$ \\
\hline Zygomatic abscess & 0 & 0 & 14 & $14(9 \%)$ \\
\hline Mastoid fistula & 0 & 0 & 14 & $23.2 \%)$ \\
\hline Labyrinthitis & 5 & 1 & 10 & 10 \\
\hline Labyrinthine fistula & 0 & 0 & 20 & $13 \%)$ \\
\hline Facial palsy & 11 & 4 & $35(22.6 \%)$ \\
\hline
\end{tabular}

mastoiditis. However, one patient had four complications together including mastoiditis, meningitis, temporal lobe abscess and lateral sinus thrombophlebitis.

The most common extracranial complication was subperiosteal abscess, followed by mastoiditis and facial palsy. There were 36 cases of mastoid abscess, two cases of Bezold's abscess and one case each of Luc's abscess and zygomatic abscess (Table 4).

All complications secondary to acute otitis media and chronic otitis media without cholesteatoma were extracranial only. Three out of 34 patients with complication from acute otitis media had multiple complications (one had facial palsy and labyrinthitis, and two had facial palsy and mastoiditis). Two of these patients had diabetes mellitus as a comorbidity. One of the seven patients with complication from chronic otitis media without cholesteatoma had two co-existing complications and they were facial palsy and mastoiditis (Table 4).

All 27 intracranial complications were from chronic otitis media with cholesteatoma. Brain abscess was the most common intracranial complication. Eight patients had brain abscess in 
Table 5. Distribution of intracranial complications $(n=27)$

\begin{tabular}{l|c}
\hline Type of intracranial complication & Frequency of complication (\%) \\
\hline Meningitis & $8(29.6)$ \\
\hline Temporal lobe abscess & $8(29.6)$ \\
\hline Cerebellar abscess & $4(14.8)$ \\
\hline Multifocal brain abscess & $1(3.7)$ \\
\hline Lateral sinus thrombophlebitis & $3(11.2)$ \\
\hline Extradural abscess & $2(7.4)$ \\
\hline Subdural abscess & $1(3.7)$
\end{tabular}

the temporal lobe, four had in the cerebellum, and one had multifocal brain abscess (Table 5). All three patients with lateral sinus thrombophlebitis had multiple complications (one had facial palsy, one had cerebellar abscess, and one had meningitis, mastoiditis, and temporal lobe abscess).

Of the 164 patients with complication, there was one mortality $(0.6 \%)$. The case was a 51 -year old male with chronic otitis media with cholesteatoma. He was a known case of diabetes mellitus with stage four chronic kidney disease on dialysis. He had grade three facial palsy with lateral sinus thrombophlebitis. The patient expired on third post-operative day following canal wall down mastoidectomy.

\section{Discussion}

Complications of otitis media can lead to various morbidities and sometimes prove lethal. In the pre-antibiotic era, the mortality from complications of otitis media was reported to be as high as $80 \%$. Survival rates were reported to improve up to $50 \%$ with the introduction of sulfonamides, and further to $80 \%$ with the introduction of penicillin (5). The incidence of intracranial complications of otitis media was reported to decline from $2.3 \%$ to $0.04 \%$ after the use of antibiotics (6). However, complications from otitis media continue to be a problem in developing countries like Nepal.

This study was conducted in Tribhuvan University Teaching Hospital, which is one of the oldest and busiest tertiary referral centers in Nepal's capital Kathmandu. The hospital also has the highest bed capacity in the country. Therefore, this study intends to be able to shed light on the changing trends of the complications in the twenty-first century in a developing country, Nepal.

A study by Kangsanarak et al. (7) in Thailand found the prevalence of complications from otitis media to be $0.69 \%$. Similarly, in our study, we found this rate to be $0.78 \%$. However, this rate is still high compared to that from developed countries. Samuel et al. (8) found the incidence of extracranial complications to be $0.13 \%$, and Palva et al. (9) reported the incidence of intracranial complications to be $0.04 \%$. In developed countries, rarity of complications limits the experience of the otologist (1).
Before the advent of antibiotics, $52 \%$ of the complications were secondary to acute otitis media. With the use of suitable antibiotics, however, complications encountered today are mostly from chronic otitis media (1). In our study, the incidence of complications from acute otitis media was found to be $0.5 \%$, while the incidence of complications from chronic otitis media with cholesteatoma was found to be $5.6 \%$. This difference between the rates of complications from acute and chronic otitis media may be due to the use of antibiotics and the routine vaccination against Haemophilus influenza and Streptococcus pneumoniae. Chronic otitis media without cholesteatoma is referred to as the safer type of otitis media, but complications may nevertheless occur. Complications in non-cholesteatomatous otitis media usually occur in neglected cases of tubotympanic disease. The incidence of complications in chronic otitis media without cholesteatoma in this study was $0.06 \%$.

The complications of acute and chronic otitis media were highest in the population under 20 years of age (48.28\%). Also, 50\% of the complications from acute otitis media were seen in $\mathrm{pa}^{-}$ tients aged younger than 20 years. This finding of our study is comparable to that reported by Osma et al. (6), where $58 \%$ of patients with complication were under 20 years of age. In our study, $74 \%$ of intracranial complications were seen in patients under 20 years of age. Samuel et al. (8) reported $74 \%$ of intracranial complications occurring in children and young adults in their study. Complications are more commonly seen in children than in adults given the increased frequency of otitis media in children due to immature Eustachian tube, low immunity, the aggressive nature of paediatric cholesteatoma, well-pneumatized paediatric temporal bone where spread of cholesteatoma becomes easy, and greater inflammatory markers in paediatric cholesteatoma (10).

In a study by Singh and Maharaj (5) with 268 patients in 1993, $32 \%$ had extracranial complications, $56 \%$ had intracranial complications, and $12 \%$ had combined extracranial and intracranial complications. This report contrasts with our study where we found 131 (80\%) patients with extracranial complications, 18 (11\%) with intracranial complications, and 15 (9\%) with multiple complications. In 2011, Wu et al. (11) reported that extracranial complications had gradually increased, whereas intracranial complications had gradually decreased during their 22 -year study. The decrease in intracranial complications may be due to the early administration of higher generation antibiotics, the widespread use of high-esolution imaging, and the improvement in microsurgical techniques.

The clinician should be vigilant about the possibility of more than a single complication in patients. Mostafa et al. (12) reported two concurrent complications in 54\%, and three or more concurrent complications in $44.7 \%$ of their 422 patients. $\mathrm{Wu}$ et al. (11) had multiple complications in $10 \%$ of their patients, which is a finding comparable to that found in our study. Facial palsy was the most common concurrent complication in our 
study. Thorough history taking and detailed clinical examination are mandatory in all patients, to avoid missing out on multiple complications. Sometimes the use of antibiotics can mask the signs and symptoms of complications. Magnetic resonance imaging of the brain is mandatory in addition to high-resolution computed tomography (HRCT) of the temporal bone and should be performed early if the clinician suspects intracranial complication since early intervention reduces morbidity and mortality.

In our study, subperiosteal abscess was the most common extracranial complication, which is comparable to the reports of Osma et al. (6) and Rupa and Raman (13). This tends to vary in other studies, e.g., facial palsy and labyrinthitis were reported as the most common extracranial complications by Kangsanarak et al. (7) and Wu et al. (11). The most common intracranial complication in our study was brain abscess, which is similar to the other reports $(6,11,13)$ The most common sites of brain abscess were the temporal lobe, followed by the cerebellum. Sometimes multifocal brain abscess may occur. Kangsanarak et al. (7) reported meningitis and Mostafa et al. (12) reported lateral sinus thrombophlebitis to be the most common intracranial complications.

The complications in relation to mastoid could range from the stage of mastoiditis, subperiosteal abscess formation to mastoid fistula formation. In our study, most of the patients with chronic otitis media with cholesteatoma presented in the stage of subperiosteal abscess; however, patients presenting in the stage of mastoiditis were also common. All 14 patients presenting with mastoid fistula were suffering from chronic otitis media with cholesteatoma and had been unaware of their ear discharge for a long time. In our study, mastoiditis was the most common extracranial complication of acute otitis media, followed by facial palsy and labyrinthitis. It is important to note that $6 \%$ to $17 \%$ of the patients diagnosed as acute mastoiditis may develop intracranial complications (14). Therefore, early management of a mastoid related complication is essential.

Facial nerve palsy was the second most common complication from chronic otitis media and acute otitis media in our study. All patients in our study had incomplete (grade 3 to 4) facial palsy. The frequency of facial paralysis in different studies range from $0.16 \%$ to $2.62 \%$ (2). A study performed by Smith and Danner (15) reported that facial palsy in children due to acute otitis media is incomplete, occurs abruptly and has good recovery, whereas facial palsy due to chronic otitis media occurs slowly and has worse prognosis. With the use of antibiotics, the episodes of acute otitis media have declined and so has facial palsy. $80 \%$ of patients with facial palsy from acute otitis media recover with intravenous antibiotics and ventilation tube insertion (14). The remainder of patients require cortical mastoidectomy. Facial nerve decompression is usually not advocated in facial palsy from acute otitis media, and the role of corticosteroids seems controversial. The treatment of facial palsy from chronic otitis media is always surgical and should be done promptly to get good recovery (2). The role of facial nerve decompression is controversial, as some groups advocate routine decompression, while other groups advocate that only removal of the disease is sufficient.

Baysal et al. (16) reported the incidence of labyrinthitis to range from $12.8 \%$ to $34 \%$. Labyrinthitis was the third most common extracranial complication from acute and chronic otitis media in our study. Patients with labyrinthitis from chronic otitis media with cholesteatoma were treated with intravenous antibiotics, labyrinthine sedatives, and canal wall down mastoidectomy, while surgery was not performed in patients with labyrinthitis from acute otitis media and chronic otitis media without cholesteatoma.

In our study, all labyrinthine fistula cases were caused by chronic otitis media with cholesteatoma, and fistula was seen in the lateral semicircular canal. The incidence of labyrinthine fistulae is $4 \%$ to $13 \%$ (2). The sensitivity of HRCT in detecting a fistula is $57 \%$ to $60 \%$ (15). All patients with labyrinthine fistula underwent canal wall down mastoidectomy with removal of the disease overlying the fistula, and repair with temporalis muscle and fascia. The removal of the disease from the semicircular canal should be done cautiously because of the risk of causing sensorineural hearing loss (15).

Brain abscess, which is a serious complication, was the most common intracranial complication in our study. The commonest site of brain abscess was the temporal lobe, followed by the cerebellum. The rate of mortalities from brain abscess was reported by Kangsanarak et al. (7) as 33\% and by Osma et al. (6) as $20 \%$. There was no mortality in our study from brain abscess. A multidisciplinary team comprising an otorhinolaryngologist, a neurosurgeon, a critical care physician, an anaesthesiologist, a radiologist and an ophthalmologist is required for the proper management of such a case. Previously, mastoid exploration was recommended to be delayed until the patient recovers after brain abscess drainage. The current recommendation, however, is to perform mastoidectomy in the same session as the brain abscess drainage if the patient can tolerate general anaesthesia (15).

Osma et al. (6), Kangsanarak et al. (7), Dubey and Larawin (17), and Lin et al. (18) reported meningitis to be the most common intracranial complication. In our study, meningitis was the second most common intracranial complication. The mortality rate of meningitis in the pre-antibiotic era was 35\% and declined to $5 \%$ with the use of antibiotics (15). Ibrahim et al. (19) reported the incidence of meningitis from acute otitis media as $13 \%$, and from chronic otitis media as 3\%. Early treatment is necessary to reduce mortality and its sequelae. Surgical intervention is recommended after the patient improves with intravenous antibiotics. 
Lateral sinus thrombosis comprises $17 \%$ to $19 \%$ of the intracranial complications (15). High index of suspicion is required, because nowadays the previously described classical clinical presentation is rare due to the use of antibiotics. Magnetic resonance venography should be done to see the patency of the venous sinuses. There were three cases of lateral sinus thrombosis from chronic otitis media with cholesteatoma in our study and all of them coexisted with other complications such as facial palsy, cerebellar abscess and meningitis, mastoiditis, and temporal lobe abscess. There was one mortality in our study, which was a case of lateral sinus thrombosis with facial palsy. The mortality rate of lateral sinus thrombosis was reported as $10 \%$ by Samuel et al. (8). The role of exposing the sigmoid sinus with evacuation of the clot is debatable and currently conservative surgery seems to be sufficient (2). Systemic anticoagulants should be used in selected cases only, such as involvement of the sagittal sinus or a persistent rise in intracranial pressure (15).

There were two cases of extradural abscess and one case of subdural abscess in our study. Neurosurgical procedure was performed initially followed by canal wall down mastoidectomy.

The mortality from otitis media is usually secondary to intracranial complications. Mortality rate has reduced from $75 \%$ in the pre-antibiotic period to $5 \%$ in the antibiotic period in developed countries (14). The mortality rate in our study was $0.6 \%$. The low mortality rate in our study could be due to the lower incidence of intracranial complications compared to extracranial complications, as well as prompt treatment of patients, improved microsurgical techniques and critical care services in our center.

The limitations of this study are its retrospective nature and the disproportion between the sample sizes of the acute and chronic otitis media groups. In the future, prospective studies on the impact of routinely administrated pneumococcal conjugate vaccine in complications from otitis media may be performed.

\section{Conclusion}

The incidence of complications due to chronic otitis media with cholesteatoma is higher as compared to that of acute otitis media and chronic otitis media without cholesteatoma. Extracranial complications are common as compared to intracranial complications. However, multiple complications may occur. Otorhinolaryngologists should be aware about the possibility of masking of the symptoms and the absence of classical clinical presentation with the use of antibiotics.

Ethics Committee Approval: Ethics committee approval was received for this study from the Institutional Review Committee of Institute of Medicine, Tribhuvan University (Approval Date: January 7, 2020; Approval Number: 278(6-11)E2 076/077).

Informed Consent: Informed consent was obtained from the patients who participated in this study.
Peer-review: Externally peer-reviewed.

Author Contributions: Concept - K.D., P.R.; Design - K.D.; Supervision - P.R., U.G.; Materials - P.R.; Data Collection and/or Processing - K.D.; Analysis and/or Interpretation - K.D., P.R., U.G.; Literature Search - K.D., P.R., U.G.; Writing - K.D.; Critical Reviews - P.R., U.G.

Conflict of Interest: The authors have no conflicts of interest to declare.

Financial Disclosure: The authors declared that this study has received no financial support.

\section{References}

1. Kumar A, Wiet R. Aural Complications of otitis media. Gulya AJ, Minor LB, Poe DS, editors. Glasscock-Shambaugh Surgery of the Ear. 6th ed. Connecticut: People's Publishing House; 2010. p. 437-50.

2. Browning GG, Weir J, Kelly G, Swan IRC. Chronic otitis media. Watkinson JC, Clarke RW, editors. Scott-Brown's Otorhinolaryngology Head \& Neck Surgery. 8th ed. Vol 2. Roca Raton: CRC Press; 2018. p. 977-1020.

3. Yorgancilar E, Yildirim M, Gun R, Bakir S, Tekin R, Gocmez C, et al. Complications of chronic suppurative otitis media: a retrospective review. Eur Arch Otorhinolaryngol 2013; 270: 69-76.

4. Sharma N, Jaiswal AA, Banerjee PK, Garg AK. Complications of chronic suppurative otitis media and their management: a single institution 12 years experience. Indian J Otolaryngol Head and Neck Surg 2015; 67: 353-60.

5. Singh B, Maharaj TJ. Radical mastoidectomy: its place in otitic intracranial complications. J Laryngol Otol 1993; 107: 1113-8.

6. Osma U, Cureoglu S, Hosoglu S. The complications of chronic otitis media: report of 93 cases. J Laryngol Otol 2000; 114: 97-100.

7. Kangsanarak J, Fooanant S, Ruckphaopunt K, Navacharoen N, Teotrakul S. Extracranial and intracranial complications of suppurative otitis media. Report of 102 cases.J Laryngol Otol 1993; 107: 999-1004.

8. Samuel J, Fernandes CM, Steinberg JL. Intracranial otogenic complications: a persisting problem. Laryngoscope 1986; 96: 2728.

9. Palva T, Virtanen H, Mäkinen J. Acute and latent mastoiditis in children. J Laryngol Otol 1985; 99: 127-36.

10. Hellier WPL. Chronic otitis media. Watkinson JC, Clarke RW, editors. Scott-Brown's Otorhinolaryngology Head \& Neck Surgery. 8th ed. Vol 2. Roca Raton: CRC Press; 2018. p.155-64.

11. Wu JF, Jin Z, Yang JM, Liu YH, Duan ML. Extracranial and intracranial complications of otitis media: 22-year clinical experience and analysis. Acta Otolaryngol 2012; 132: 261-5.

12. Mostafa BE, El Fiky LM, El Sharnouby MM. Complications of suppurative otitis media: still a problem in the 21 st century. ORL J Otorhinolaryngol Relat Spec 2009; 71: 87-92.

13. Rupa V, Raman R. Chronic suppurative otitis media: complicated versus uncomplicated disease. Acta Otolaryngol 1991; 111: 530-5.

14. Rea PA, Ronan N. Acute otitis media. Watkinson JC, Clarke RW, editors. Scott-Brown's Otorhinolaryngology Head \& Neck Surgery. 8th ed. Vol 2. Roca Raton: CRC Press; 2018. p. 137-54.

15. Smith JA, Danner CJ. Complications of chronic otitis media and cholesteatoma. Otolaryngol Clin North Am 2006; 39: 1237-55. 
Dongol et al.

16. Baysal E, Erkutlu I, Mete A, Alptekin M, Oz A, Karataş ZA, et al. Complications and treatment of chronic otitis media. J Craniofac Surg 2013; 24: 464-7.

17. Dubey SP, Larawin V. Complications of chronic suppurative otitis media and their management. Laryngoscope 2007; 117: 264-7.
18. Lin YS, Lin LC, Lee FP, Lee KJ. The prevalence of chronic otitis media and its complication rates in teenagers and adult patients. Otolaryngol Head Neck Surg 2009; 140: 165-70.

19. Ibrahim SI, Cheang PP, Nunez DA. Incidence of meningitis secondary to suppurative otitis media in adults. J Laryngol Otol 2010; 124: $1158-61$. 